\title{
Pengembangan Kawasan Tanah Lemo Dan Ara Sebagai Pusat Industri Kerajinan Miniatur Kapal Phinisi Di Kecamatan Bontobahari Kabupaten Bulukumba
}

\author{
Baharuddin*, Lukman Bochari, M. Rizal Firmansyah \\ Teknik Sistem Perkapan, Fakultas Teknik Kampus Gowa
}

\begin{abstract}
Abstrak
Kawasan Tanah Lemo dan Desa Ara terletak di Kecamatan Bonto Bahari kabupaten Bulukumba. Kawasan ini sangat memungkinkan untuk kembangkan menjadi pusat industri pembuatan miniatur kapal Phinisi, mengingat tanah Bulukumba dikenal memiliki nilai historis yang melekat kuat dengan budaya panrita lopi (ahli pembuat perahu). Potensi yang paling terkenal di Kecamatan Bonto Bahari yaitu industri pembuatan Kapal Phinisi. Kawasan Industri Kapal Phinisi di Kecamatan Bonto Bahari saat ini salah satunya berada di Kelurahan Tanah Lemo. Karena kemahiran masyarakat Tanah Lemo dalam pembuatan Kapal Phinisi secara turun temurun.

Selain sebagai upaya pelestarian budaya, komoditi bisnis miniatur kapal phinisi ini memiliki potensi ekonomi karena adanya peningkatan jumlah kunjungan wisatawan yang cukup signikan pada beberapa tahun terakhir ini ke kabupaten Bulukumba. Letak Lemo dapat dikembangkan sebagai pusat industri Miniatur Kapal Phinisi di Kecamatan Bonto Bahari Kabupaten Bulukumba. Masalah ini dilihat dengan kondisi kawasan pantai dan pembuatan miniatur kapal yang masih semraut, sementara ada potensi lain yang dapat menunjang perkembangan pembuatan Kapal Phinisi, agar kedepannya kawasan ini dapat lebih berkembang maka diperlukan arahan pengembangan.

Adapun hasil dsikusi untuk kedepannya adalah pengembangan sarana dan prasarana khususnya jaringan jalan sebagai akses dari tempat pembuatan Kapal Phinisi dan menuju pantai Lemo - Lemo, pengembangan dalam sektor perikanan tangkap dalam membantu menunjang perekonomian masyarakat kawasan pantai Tanah Lemo, pengembangan kawasan pembuatan Kapal Phinisi, Pengembangan wisata alam pantai Lemo - Lemo. Melakukan promosi tentang potensi sumberdaya alam yang dimiliki kawasan pantai Tanah Lemo, agar kedepannya kawasan pantai Tanah Lemo dapat menjadi kawasan wisata budaya dan wisata alam. Serta pentingnya menjaga kebersihan lingkungan, khususnya di kawasan pantai Tanah Lemo.
\end{abstract}

Kata Kunci: Pusat industri miniatur kapal; kapal Phinisi.

\begin{abstract}
The Tanah Lemo and Ara village area are located in Bonto Bahari District, Bulukumba Regency. This area is very possible to develop into the center of the Phinisi ship miniature manufacturing industry, considering that the land of Bulukumba is known to have a historical value that is strongly attached to the culture of panrita lopi (expert boat maker). The most famous potential in the District of Bonto Bahari is the Phinisi Shipbuilding industry. The phinisi ship industrial area in Bonto bahari district is currently located in Tanah Lemo Sub-District. Because of the proficiency of the Tanah Lemo community in making phinisi ship from generation to generation.

Aside from being an effort to preserve culture, this miniature phinisi ship business commodity has bcome an economic potential due to increase the number of tourist visits which quite significant in recent years to Bulukumba district. The location of Lemo can be developed as the center of the Phinisi Ship Miniature industry in the District of Bonto Bahari, Bulukumba Regency. This problem seen with the condition of the coastal area and the manufacture of miniature ships that are still in the same condition, while there are other potentials that can support the development of Phinisi ship building, so that in the future this area can be more developed, development direction is needed.

The results of the discussion for the future are the development of facilities and infrastructure, especially the road network as access from the Phinisi Shipbuilding site and towards Lemo-Lemo beach, development in the capture fisheries sector to help support the economy of the Tanah Lemo coastal area, development of the Phinisi Shipbuilding area, tourism development natural beach Lemo - Lemo. Promoting the potential of natural resources owned by the Tanah Lemo beach area, so that in the future the Tanah Lemo beach area can become a cultural and natural tourism area. And the importance of maintaining environmental cleanliness, especially in the Tanah Lemo beach area.
\end{abstract}




\section{PENDAHULUAN}

Kelurahan tanah Lemo dan Desa Ara merupakan dua desa yang berada di Kecamatan Bontobahari Kabupaten Bulukumba. Kedua desa di atas termasuk dalam daerah administratif Kecamatan Bontobahari, kabupaten Bulukumba, Provinsi Sulawesi selatan. Jarak antara pusat desa dengan ibu kota kabupaten Bulukumba di tempuh melalui perjalanan darat sejauh kurang lebih $37 \mathrm{~km}$.

Wilayah kedua desa termasuk wilayah pesisir dimana berhadapan langsung dengan laut flores memiliki berbagai potensi sumber daya yang siap dikembangkan. pemerintah Kabupaten Bulukumba melalui Peraturan Daerah No. 21 Tahun 2012 tentang Rencana Tata Ruang Wilayah Kabupaten Bulukumba Tahun 2012 - 2032 mengarahkan Kelurahan Tanah Lemo sebagai tempat pembuatan Kapal Phinisi sebagai kawasan strategis kabupaten dari sudut kepentingan sosial budaya.

Potensi yang paling terkenal di Kecamatan Bonto Bahari yaitu industri pembuatan Kapal Phinisi. Kawasan Industri Kapal Phinisi di Kecamatan Bonto Bahari saat ini salah satunya berada di Kelurahan Tanah Lemo. Karena kemahiran masyarakat Tanah Lemo dalam pembuatan Kapal Phinisi secara turun temurun, maka Adapun penggunaan lahan eksisting di Kelurahan Tanah Lemo yaitu permukiman/perkampungan, tambak, kebun campuran, sawah, kebun kelapa dan hutan belukar/alang - alang. Namun disamping itu terdapat pula potensi wisata pantai di Kelurahan Tanah Lemo, yaitu pantai Lemo Lemo, dengan jarak dari kawasan pembuatan Kapal Phinisi sekitar 7 Km. Pantai LemoLemo potensial dijadikan tempat wisata karena berbagai daya tarik wisata dapat dilihat di sini. Selain keindahan pantainya, di tempat ini dapat terasa kesejukan udara hutan lindung dan kicau burung yang merdu. Bukan hanya itu, pantai ini memiliki terumbu karang yang indah dengan berbagai jenis ikan hias. Di sore hari dapat terlihat panorama senja, di saat matahari akan terbenam. Kombinasi hutan dan pantai menjadikan kawasan ini berpotensi untuk dikembangkan. Namun pada kenyataannya pantai ini kurang dilirik oleh wisatawan, Oleh karena itu dengan adanya potensi wisata pantai Lemo - Lemo dan kawasan pembuatan Kapal Phinisi, maka diharapkan kedepannya kawasan pantai Tanah Lemo dapat dikembangkan, karena selain menikmati indahnya panorama pantai Lemo - Lemo, juga dapat melihat proses pembuatan Kapal Phinisi. Berdasarkan ketetapan dari RTRW Kabupaten Bulukumba tahun 2012 dari sudut kepentingan sosial budaya yang menetapkan Kelurahan Tanah Lemo sebagai pusat industri Kapal Phinisi, dan potensi wisata pantai Lemo - Lemo, perlu adanya arahan pengembangan, agar kedepannya selain pembuatan Kapal Phinisi juga pantai Lemo - Lemo dapat menjadi tujuan wisata, dan ini perlu dukungan dari pemerintah setempat untuk mewujudkan hal tersebut, yang dalam pengembangannya tidak menimbulkan dampak bagi lingkungan sekitar.

Oleh karena nilai - nilai dan pengetahuan - pengetahuan yang diturunkan dari generasi - ke generasi tentunya terdapat suatu perkembangan maka terkait dengan kawasan pantai Tanah Lemo pun perlu adanya pengembangan agar kedepannya pantai ini menjadi salah satu tujuan wisata alam dan wisata budaya dengan tetap menjaga kelestarian lingkungan di kawasan pantai dan sekitarnya, dan terkait dengan industri Kapal Phinisi maka diharapkan slogan kebanggaan dari Kabupaten Bulukumba sebagai "Butta Panrita Lopi" tetap bertahan. Sehubungan dengan hal tersebut maka peneliti mengangkat judul tentang "Studi Pengembangan Kawasan Pantai Tanah Lemo sebagai Pusat Industri Kapal Phinisi di Kecamatan Bonto Bahari Kabupaten Bulukumba 
Penelitian ini bertujuan untuk mengetahui pemanfaatan ruang kawasan antai Tanah Lemo Kecamatan Bonto Bahari Kabupaten Bulukumba sebagai pusat industri Kapal Phinisi dan pengembangan kawasan pantai Tanah Lemo sebagai pusat industri Kapal Phinisi di Kecamatan Bonto Bahari Kabupaten Bulukumba.

\section{METODE}

\section{Lokasi dan Waktu}

Penelitian ini dilaksanakan di Kawasan Pantai Tanah Lemo Kecamatan Bonto Bahari Kabupaten Bulukumba.Penentuan lokasi tempat penelitian dimaksudkan untuk memfokuskan ruang lingkup pembahasan dan sekaligus mempertajam masalah yaitu bagaimana arahan pengembangan kawasan pantai Tanah Lemo sebagai pusat industri kapal phinisi.

\section{Jenis dan Sumber Data}

Jenis data yang digunakan dalam penelitian ini dibedakan atas dua jenis data yaitu:

a. Data Kualitatif adalah jenis data yang tidak berupa angka tetapi berupa kondisi kualitatif objek dalam ruang lingkup penelitian baik dalam bentuk uraian kalimat ataupun penjelasan meliputi pola penggunaan lahan, batas wilayah, kondisi fisik wilayah, keadaan topografi, kemiringan lereng, dan geologi dan jenis tanah dan hidrologi.

b. Data kuantitatif adalah jenis data yang berupa angka atau numerik yang bisa diolah dengan menggunakan metode perhitungan yang sederhana. Data ini meliputi jumlah dan kepadatan penduduk, luas wilayah dan persentase penggunaan lahan.

Jenis data yang digunakan dalam penelitian ini dibedakan atas dua jenis data yaitu:

a. Data primer merupakan data yang diperoleh melalui observasi lapangan atau pengamatan langsung objek penelitian. Survei ini dilakukan untuk mengetahui kondisi kualitatif objek studi. Data primer yang dibutuhkan antara lain;

1)Data penggunaan lahan/eksisiting

2)Kondisi fisik dasar wilayah serta kondisi karakteristik wilayah pesisir.

b. Data Sekunder adalah data yang diperoleh melalui instansi-instansi yang terkait dengan penelitian. Data yang dimaksud seperti:

1)Data Demografi Penduduk Kawasan Pesisir

2)Luas wilayah dan persentase penggunaan lahan.

3)Peta-peta yang mendukung penelitian.

\section{Metode Analisis}

Analisis yang digunakan untuk menjawab tujuanpada penelitian ini terdiri dari:

Metode analisis deskriptif kualitatif merupakan bahagian dari metode analisis kuantitatif dengan menjabarkan analisis secara deskriptif kualitatif sehingga lahirlah suatu konsep dan sebagai dasar dalam analisis selanjutnya.

Analisis Matriks SWOT adalah identifikasi berbagai faktor secara sistematis untuk merumuskan strategi pengembangan (Rangkuti, 2008:19). Analisis ini didasari atas logika yang dapat memaksimalkan kekuatan dan peluang, serta meminimalkan kelemahan dan ancaman. Analisis situasi internal (faktor-faktor kekuatan dan kelemahan) dikombinasikan dengan situasi eksternal (faktor-faktor peluang dan ancaman) akan menghasilkan beberapa strategi alternatif pengembangan. 
Jurnal Tepat (Teknologi Terapan Untuk Pengabdian Masyarakat), Volume 2, Nomor 1, Tahun 2019

\section{HASIL DAN PEMBAHASAN}

\section{Analisis Kondisi Fisik Dasar}

a. Topografi dan Kelerengan

Berdasarkan hasil survei lapangan menunjukkan bahwa daerah datar dengan tingkat kemiringan 0 - 25\% masih didominasi oleh lahan permukiman berupa areal Perkantoran, Pendidikan, dan perdagangan, sedangkan daerah pesisir menjadi kawasan pembuatan perahu dan berpotensi dalam pengembangan wisata alam pantai Lemo Lemo. Kemiringan lereng Kelurahan Tanah Lemo berada pada kemiringan $0-2 \%$ hingga 2-15\%. Dengan kondisi demikian menjadikan kawasan pantai Tanah Lemo selain tempat pembuatan Kapal Phinisi juga dapat dikembangkan untuk kawasan wisata alam yaitu pantai Lemo - Lemo, serta diperuntukkan untuk permukiman, pariwisata, serta kawasan hutan.

b. Jenis Tanah

Jenis tanah di Kelurahan Tanah Lemo berdasarkan data terbentuk dari batu lumpur yang mengandung sejumlah variabel tanah liat dan aragonit, dan sangat peka terhadap erosi dan memungkinkan untuk pengembangan usaha pertanian dan perkebunan.

c. Hidrologi

Dari hasil survey lapangan, diketahui bahwa kedalaman air tanah di daerah yang bukan pesisir berkisar antara 4-7,5 meter dari permukaan tanah, sedangkan di daerah pesisir berkisar antara 5 - 10 meter. Kondisi ini dimanfaatkan sebagian masyarakat sebagai sumber air bersih berupa sumur gali, tapi untuk kawasan pantai Tanah Lemo masih sulit dalam memperoleh air bersih, ini disebabkan adanya interusi air laut karena Kelurahan Tanah Lemo berbatasan langsung dengan pantai, dengan kondisi seperti itu sebagian tetap mengandalkan air bersih dari PDAM.

d. Geologi

Berdasarkan jenis struktur batuan yang dimiliki Kecamatan Bonto Bahari dan sekitarnya, maka untuk Kelurahan Tanah Lemo memiliki jenis batuan pembentuknya sendiri, yang secara umum Kelurahan Tanah Lemo di susun oleh batuan Anggota Selayar Formasi Walanae.

\section{Analisis Kondisi Sarana dan Prasarana}

a. Sarana Pendidikan

Saat ini kondisi eksisting keberadaan sarana pendidikan masih mudah dijangkau karena lokasinya yang tidak jauh dari permukiman penduduk.

b. Sarana Kesehatan

Untuk pelayanan kesehatan di Kelurahan Tanah Lemo saat ini masih bisa dijangkau masyarakat karena masih berada dalam radius yang tidak jauh dari permukiman. Selain itu pula terdapat 1 puskesmas di Kelurahan Tanah Beru, yang bisa juga bisa melayani masyarakat yang ada di Kelurahan Tanah Lemo, karena secara administratif Kelurahan Tanah Beru berbatasan dengan Kelurahan Tanah Lemo.

c. Prasarana Jaringan Jalan

Berdasarkan data dan hasil survey lapangan, maka untuk pengembangan di kawasan pantai Tanah Lemo khususnya, perlu perbaikan prasarana jaringan jalan untuk kedepannya, karena kondisi jalan di kawasan tersebut kurang baik. Sementara untuk menuju ke pantai Lemo - Lemo menggunakan akses jalan tersebut.

\section{Analisis Pengembangan Kawasan Pantai Tanah Lemo Sebagai Pusat Industri}


Kapal Phinisi, pengembangan kawasan pantai Tanah Lemo sebagai pusat industri Kapal Phinisi ditinjau dari jumlah penduduk pada tahun 2013 adalah 4.211 jiwa dan berdasarkan proyeksi penduduk selama 20 tahun kedepan adalah 6.156 jiwa terkait dengan penggunaan lahan pada tahun 2013 atau kondisi eksisting, mengikuti pola perkembangan jalan. Ini dapat dilihat dari penggunaan lahan di Kelurahan Tanah lemo yang masih didominasi kebun campuran. Sementara untuk kegiatan industri pembuatan Kapal Phinisi volume ruang saat ini memiliki luas $\pm 0,59 \mathrm{Km} 2$, dengan luas lahan Kelurahan Tanah Lemo secara keseluruhan yaitu 15,95 Km2. Asumsi luas lahan untuk pembuatan 1 Kapal Phinisi dengan ukuran 50 ton yaitu $\pm 0,050 \mathrm{Km} 2$. Jadi untuk membuat 10 buah Kapal Phinisi membutuhkan luas lahan sekitar 0,5 Km2. Sedangkan lahan untuk pembuatan Kapal Phinisi saat ini yaitu 0,59 Km2, yang juga tidak terlepas dari penyimpanan bahan baku pembuatan kapal, dan limbah yang dibuang, dengan demikian pembuatan Kapal Phinisi di kawasan pantai Tanah Lemo \pm 10 buah untuk 1 kali pesanan. Dengan kondisi demikian, maka kedepannya diperlukan pengembangan, agar produksi Kapal Phinisi di kawasan pantai Tanah Lemo bisa meningkat dari sebelumnya, selain meningkatkan perekonomian masyarakat sekitar, juga bisa menjadikan kawasan pantai Tanah Lemo sebagai pusat industri Kapal Phinisi, yang tentunya tidak lepas dari tujuan pembangunan dan pengembangan industri itu sendiri, Dan prinsip - prinsip pengembangan industri yaitu : keberlanjutan, aman, kedekatan dengan aglomerasi aktivitas perekonomian masyarakat, nyaman, serta industri harus berwawasan lingkungan. Kemudian perlu adanya keterpaduan, baik keterpaduan secara horisontal atau daerah di sekitar kawasan pantai Tanah Lemo yang bisa menjadi penunjang bagi perkembangan kawasan pantai itu sendiri, maupun keterpaduan secara vertikal yaitu pengelolaan dan pengembangan kawasan pantai Tanah Lemo tidak boleh bertentangan dengan tingkat atasnya, dan justru harus merupakan satu kesatuan yang tak terpisahkan.

Oleh karena Kelurahan Tanah Lemo terbagi dalam 4 Lingkungan dan 3 Lingkungan termasuk dalam kawasan pesisir pantai Tanah Lemo, maka untuk pengembangan industri kapal Phinsi berada pad Lingkungan Tokambang sesuai kondisi eksisting yang tentunya ditunjang dengan sarana dan prasarana penunjang industri pembuatan Kapal Phinisi. Dan untuk mendukung pengembangan kawasan pantai Tanah Lemo sebagai pusat industri Kapal Phinisi, tentunya tidak mengesampingkan potensi sumberdaya alam yang lain, yaitu pantai Lemo - Lemo.

Dengan adanya potensi ini bisa menjadikan kawasan pantai Tanah Lemo sebagai kawasan wisata budaya dan wisata alam, karena dilain sisi bisa melihat proses pembuatan Kapal Phinisi, kita juga bisa menikmati hamparan pantai Lemo - Lemo. Ditinjau dari penggunaan lahan di kawasan pantai dan tujuan dari pembangunan dan pengembangan industri maka tujuan utama dari pengembangannya adalah menyejahterakan masyarakat dengan menyeimbangkan antara pengembangan kawasan industri dan pengembangan potensi pantai Lemo - Lemo. Karena dengan adanya potensi tersebut mampu mendongkrak pengembangan kawasan pantai Tanah Lemo sebagai pusat industri Kapal Phinisi. Disamping itu perlu pula diperhatikan aspek lingkungan di kawasan Pantai Tanah Lemo terutama di kawasan industri, perlu pengolahan limbah buangan industri pembuatan Kapal Phinisi. Agar limbah dari pembuatan Kapal Phinisi tersebut tidak mencemari lingkungan di kawasan Pantai Tanah Lemo. Dengan adanya pengembangan pada kawasan Pantai Tanah Lemo sebagai pusat industri Kapal Phinsi, maka mampu menunjang perekonomian masyarakat di Kelurahan Tanah Lemo khususnya, yang dulunya hanya menjadi petani atau nelayan, namun dengan adanya pengembangan di kawasan tersebut kini bisa menjadi pengrajin / pembuat Kapal Phinisi, dan juga dapat membuka usaha pembuatan miniatur dari Kapal Phinisi itu sendiri. 


\section{Strategi Pengembangan Kawasan Pantai Tanah Lemo}

Dalam pengembangan kawasan pantai Tanah Lemo perlu adanya strategi dalam mendukung kegiatan tersebut agar dapat memberikan pengaruh bagi peningkatan kualitas lingkungan kawasan pantai. Strategi tersebut harus dibarengi dengan peningkatan sarana dan prasarana penunjang sehingga mampu mengoptimalkan segala potensi yang dimiliki kawasan pantai Tanah Lemo dalam pengembangannya. Berikut ini tabel analisis SWOT pengembangan Kawasan Pantai Tanah Lemo.

Dari tabel maka dapat diketahui strategi - strategi arahan pengembangan kawasan pantai Tanah Lemo, dari hasil memaksimalkan kekuatan dan memaksimalkan peluang maka adapun strateginya yaitu strategi $\mathrm{S}-\mathrm{O}$, antara lain:

a. Pengembangan sarana dan prasarana khususnya jaringan jalan sebagai akses dari tempat pembuatan Kapal Phinisi dan menuju pantai Lemo - Lemo.

b. Pengembangan dalam sektor pertanian dan perkebunan serta perikanan tangkap dalam menunjang perekonomian masyarakat kawasan pantai Tanah Lemo.

c. Pengembangan kawasan pembuatan Kapal Phinisi d. Pengembangan wisata alam pantai Lemo - Lemo

Melakukan promosi tentang potensi sumberdaya alam yang dimiliki kawasan pantai Tanah Lemo, agar kedepannya kawasan pantai Tanah Lemo dapat menjadi kawasan wisata budaya dan wisata alam. Serta pentingnya menjaga kebersihan lingkungan, khususnya di kawasan pantai Tanah Lemo.

\section{PENUTUP}

Berdasarkan hasil penelitian maka adapun arahan pengembangan kawasan pantai Tanah Lemo yaitu:

a. Pengembangan sarana dan prasarana khususnya jaringan jalan sebagai akses dari tempat pembuatan Kapal Phinisi dan menuju pantai Lemo - Lemo.

b. Pengembangan dalam sektor perikanan tangkap dalam membantu menunjang perekonomian masyarakat kawasan pantai Tanah Lemo.

c. Pengembangan kawasan pembuatan Kapal Phinisi

d. Pengembangan wisata alam pantai Lemo - Lemo

e. Melakukan promosi tentang potensi sumberdaya alam yang dimiliki kawasan pantai Tanah Lemo, agar kedepannya kawasan pantai Tanah Lemo dapat menjadi kawasan wisata budaya dan wisata alam. Serta pentingnya menjaga kebersihan lingkungan, khususnya di kawasan pantai Tanah Lemo.

\section{DAFTAR PUSTAKA}

Agus Pratikto, Widi M.Sc, Ph.D, Ir. dkk. 1993. Perencanaan Fasilitas Pantai dan Laut: Surabaya

Aksarahadi, Aswin. 2003. Studi Pemanfaatan Lahan Kawasan Pesisir Pantai

Kecamatan Bonto Bahari Kabupaten Bulukumba. Skripsi Sarjana. Fakultas Teknik. Universitas 45: Makassar

Departement Kelautan dan Perikanan. 2008 Panduan Teknis Perencanaan Tata Ruang Wilayah Pesisir dan Pulau - Pulau Kecil: Jakarta

Jumdesi Damayanti, Rabeah. 2012. Arahan Penataan Ruang Kawasan Pesisir Berdasarkan Kesesuaian Lahan di Kecamatan Ternate Selatan Kota Ternate Provinsi Maluku Utara. Skripsi Sarjana. Fakultas Teknik. Universitas 45: Makassar 
Departemen permukiman dan prasarana wilayah direktorat jenderal penataan ruang; Pedoman Pengendalian Pemanfaatan Ruang di Kawasan Rawan Bencana Banjir. Jakarta 2003

PSDAL UNHAS dengan Direktorat Bina Tata Perkotaan dan Pedesaan Departement Pekerjaan Umum. 1997: Ujung Pandang

Pusat Studi Lingkungan Hidup UNHAS, 1997. Studi Sosial Ekonomi dan Lingkungan di Kawasan Pesisir dan Laut, Makassar

Rencana Tata Ruang Wilayah (RTRW) Kabupaten Bulukumba Tahun 2012 - 2032

Republik Indonesia, Undang - Undang Nomor 24 Tahun 2007 tentang Tentang Pengelolaan Wilayah Pesisir dan Pulau-Pulau Kecil

Republik Indonesia, Undang - Undang Nomor 5 Tahun 1984 tentang Perindustrian Soewadji, MA, Jusuf. 2012. Pengantar Metodologi Penelitian: Jakarta

Supriadi, Aden. 2012. Studi Pengembangan dan Penataan Kawasan Pantai Barombong. Skripsi Sarjana. Fakultas Sains dan Teknologi. Universitas Islam Negeri

Alauddin Makassar: Makassar

Triadmodjo, Bambang. 1999. Teknik Pantai: Yogyakarta 